\title{
The nutrition transition in the Republic of Ireland: trends in energy and nutrient supply from 1961 to 2007 using Food and Agriculture Organization food balance sheets
}

\author{
Tony Sheehy ${ }^{1 *}$ and Sangita Sharma ${ }^{2}$ \\ ${ }^{1}$ School of Food and Nutritional Sciences, University College Cork, Cork, Republic of Ireland \\ ${ }^{2}$ Department of Medicine, Faculty of Medicine and Dentistry, University of Alberta, 8308-114 Street, \\ Edmonton, Alberta T6G 2V2, Canada \\ (Received 29 September 2010 - Revised 16 February 2011 - Accepted 18 February 2011 - First published online 12 April 2011)
}

\section{Abstract}

Over the course of the last 50 years the Republic of Ireland has gone from being one of the poorest countries in Europe to one of the richest; however, it is now experiencing increasing rates of obesity and non-communicable chronic disease. Although several national nutrition surveys have been carried out in Ireland since 1990, there is little information on the Irish diet before then. We analysed the FAO food balance sheets for Ireland from 1961 to 2007 in order to characterise the changes in energy and nutrient supply that took place during that period. Food balance sheets were downloaded from the FAOSTAT database and per capita supply of commodities was analysed using dietary analysis software. Energy from carbohydrate as a percentage of total energy fell from $55 \%$ in 1961 to $46 \%$ in 2007, whereas energy from fat increased from $29 \%$ to $34 \%$; these values are well outside WHO recommendations for the prevention of chronic disease. Energy from alcohol as a percentage of total energy has doubled within the last 20 years. On a nutrient-density basis, vitamins and minerals met or exceeded WHO recommendations, apart from vitamin D, folate, Ca and Fe. Although there are methodological limitations associated with the use of food balance sheets, the present results demonstrate that the current imbalances in the Irish diet were already evident several decades ago. Because they are so long established, they will be difficult to reverse unless major public health nutrition interventions are implemented.

Key words: Food balance sheets: FAOSTAT: Nutrition transition: Republic of Ireland

Over the course of the last 50 years the Republic of Ireland has gone from being one of the poorest countries in Europe to one of the richest ${ }^{(1)}$. After decades of economic stagnation and underperformance following the Second World War, an economic boom that later became known as the 'Celtic Tiger' began during the second half of the 1980s, gathered pace during the mid- and late-1990s, and continued for much of the last decade before coming to an abrupt end in 2008 due to the global financial crisis $^{(2,3)}$. At the same time as this economic transformation was taking place, a health and lifestyle transition was occurring in the Republic of Ireland that saw life expectancy at birth increase from 69.7 years in 1960 to $79 \cdot 4$ years in $2008^{(4)}$. However, there is now growing concern that these gains in life expectancy are being partly offset by increasing rates of obesity and non-communicable chronic diseases $^{(5-14)}$.

Over the last few decades there has been a sharp increase in the prevalence of obesity among both adults and children in the Republic of Ireland. In 1990, some $40 \%$ of Irish adults were overweight and a further $10 \%$ were obese ${ }^{(15)}$, whereas by 2007 the proportion of adults in the obese category had risen to $25 \%{ }^{(16)}$. Between 1970 and 2002, the average body weight of 14-year-olds in the Republic of Ireland increased by $30 \%$ in boys and by $20 \%$ in girls ${ }^{(10)}$. In 2002, some $23 \%$ of boys and $28 \%$ of girls between the ages of 4 and 16 years were either overweight or obese ${ }^{(17)}$. Between 1990 and 2005, there was a two- to fourfold increase in obesity in children aged $8-12$ years $^{(18)}$.

Excessive body fat leads to serious health consequences including CVD (mainly heart disease and stroke), type 2 diabetes, musculoskeletal disorders such as osteoarthritis, and some cancers (for example, endometrial, breast and colon) ${ }^{(19)}$. Cancer incidence and mortality rates in the Republic of Ireland are among the highest in Western Europe ${ }^{(20,21)}$, and it is estimated that one in every three individuals will develop cancer by the age of 75 years ${ }^{(21)}$. Cancer incidence increased between 1994 and 2004, with the rate for all cancers (excluding non-melanoma skin cancer) increasing by $1.4 \%$

Abbreviations: NTD, neural tube defect; QFFQ, quantitative food-frequency questionnaire.

*Corresponding author: Dr Tony Sheehy, fax +35321 4270244, email t.sheehy@ucc.ie 
per annum in males and by $1 \cdot 1 \%$ per annum in females ${ }^{(21)}$. Cancer has now overtaken CHD as the most common cause of death in the Republic of Ireland, accounting for $29 \%$ of all deaths in $2006^{(22)}$. In contrast to cancer, CHD mortality rates in the Republic of Ireland have declined in recent years, mainly due to improvements in medical treatments and favourable population changes in some risk factors, including smoking, cholesterol and blood pressure ${ }^{(12-14,23)}$. Nevertheless, CHD remains a major cause of death, accounting for $18 \%$ of deaths in $2006^{(22)}$. Moreover, there is evidence from prescription data that prevalence rates for CHD increased significantly between 1990 and $2002^{(24)}$. Prevalence rates for heart attack and angina in 2007 were $3.8 \%$ and this figure is projected to increase to $4.6 \%$ by $2020^{(25)}$. Hypertension is the most common medical condition in Ireland ${ }^{(26)}$; in 2007 its prevalence in Irish individuals aged $\geq 16$ years was $25 \cdot 1 \%^{(25)}$ and this figure is expected to rise to $28 \cdot 3 \%$ by 2020. The risk of hypertension increases dramatically with age, and recent estimates put the prevalence of hypertension in middle-aged Irish adults at approximately 50-60\% ${ }^{(16,26)}$. Diabetes prevalence in Irish adults is also increasing. In 2000, the International Diabetes Federation Atlas ${ }^{(27)}$ estimated that $3 \cdot 2 \%$ of all individuals aged $20-79$ years in the Republic of Ireland were affected by diabetes (type 1 and type 2 combined, diagnosed and undiagnosed); however, by 2010 this figure had increased to $5 \cdot 2 \%{ }^{(28)}$. Using the Public Health Observatories/Brent/ScHARR (PBS) Diabetes Population Prevalence Model $^{(29)}$, the prevalence of adult diabetes (type 1 and type 2 combined) in the Republic of Ireland in 2005 was estimated at $4.7 \%$, and it was forecast to rise to $5.9 \%$ by $2020^{(25)}$. The total direct cost of treating type 2 diabetes in 2003 was approximately $€ 580$ million, or $6 \cdot 4 \%$ of overall healthcare expenditure ${ }^{(9)}$.

Because of the fact that many chronic disease risk factors are modifiable by diet ${ }^{(30-33)}$, national nutrition surveys play an important role in epidemiological research and the development of food and nutrition policies. Over the past 60 years, six national nutrition surveys have been carried out in the Republic of Ireland ${ }^{(15,16,34-37)}$. However, all except one were carried out within the last 20 years. Thus there are major gaps in our knowledge about the nutritional composition of the Irish diet before the 1990s and about the trends that were becoming established during that time.

At their crudest level, dietary trends can be followed using national food balance sheets that are compiled annually by the $\mathrm{FAO}^{(38-40)}$. Through the use of aggregate data on food production, imports, exports and non-food utilisation, these food balance sheets provide estimates of the total amounts per head of population of the many dozens of food commodities that are available for consumption within a country during any given year. This information can be used to monitor the overall changes taking place in food and nutrient supply within $^{(41-45)}$ and between ${ }^{(46-56)}$ countries over many years. A limitation of food balance sheets is that although they provide information on per capita energy, protein and fat supply, they provide no information on carbohydrates, dietary fibre, fatty acids, amino acids, minerals or vitamins. This limitation can be overcome by coding the commodities using dietary analysis software ${ }^{(41,45)}$. The objective of the present study was to analyse the food balance sheets for the Republic of Ireland from 1961 to 2007 in order to track the changes that took place in per capita energy and nutrient supply in the country during this period. We describe these changes and discuss their implications in relation to the WHO guidelines for nutrition and prevention of chronic disease $\mathrm{e}^{(33)}$

\section{Methods}

FAO food balance sheets for the period 1961-2007 were downloaded as csv files from the FAOSTAT database ${ }^{(57)}$. These food balance sheets provide overall per capita supply (as $\mathrm{kg}$ /year) for food commodities including cereals, starchy roots, vegetables, fruits, oilseeds and oilseed oils, treenuts, animal fats, milk, meats, eggs and fish. The full list of commodities is shown in Appendix 1. Having imported the data into Microsoft Office Excel 2003 (Microsoft Corp., Redmond, WA, USA), per capita supply was then converted to $\mathrm{g} / \mathrm{d}$.

In order to determine the trends in energy and nutrient supply the commodities were coded and entered into WISP dietary analysis software (Tinuviel Software, Llanfechell, Anglesey, UK). The food composition databank supplied with this software is from McCance and Widdowson's The Composition of Foods, 5th and 6th editions plus supplements ${ }^{(58)}$. For consistency and wherever possible, foods were coded as being in their most unprocessed form (for example, 'bananas, weighed with skin', 'barley, whole grain, raw'). However, certain broad categories (such as fish, treenuts and those labelled as 'other') were lacking in detail about the specific foods that made up the category. To code these categories in a way that would reflect the Irish diet more closely we referred to the food list of a quantitative FFQ (QFFQ) that was developed recently by one of the authors (T. S.). The QFFQ is based on food intake data from three $24 \mathrm{~h}$ dietary recalls (two weekdays, one weekend day) collected in consecutive months starting in November 2008 from a non-random female university student population ( $n$ 64, aged 17-23 years) in Cork, Republic of Ireland. All foods reported more than once were included on the draft QFFQ. These foods were organised into coherent groupings to give a 207 line-item final instrument, the performance of which has since been compared and found to give good overall agreement with nutrient intakes from $4 \mathrm{~d}$ estimated food diaries in a group of forty-eight female students aged 18-25 years (T Sheehy, D Crowley, E Lally, A McAteer, E Morrisey, D O'Connor and G Tynan, unpublished results). Using the food list of this QFFQ as a guide, we populated the category 'pelagic fish' with herring, mackerel, sardines and tuna, 'demersal fish' with cod, haddock and plaice, 'freshwater fish' with salmon and trout, and 'crustaceans' with prawns, crab, lobster and shrimps. The category 'pulses (other)' was populated with split peas, lentils and chickpeas, while 'treenuts' were coded as almonds and cashew nuts. The category 'vegetables (other)' was populated with cabbage, carrots, broccoli, Brussels sprouts, cauliflower, celery, parsnip, turnip, courgette, leeks, mushrooms, beetroot, spinach, cucumber and lettuce. 'Fruits (other)' contained blackcurrants, 
currants, kiwi fruit, peaches, nectarines, plums, raspberries, strawberries, pears and watermelon, while 'citrus (other)' contained satsumas. For categories where this procedure was carried out, supply was divided equally among the constituent foods; none of these categories contributed more than about $1 \%$ of energy. Overall, the commodities we coded accounted for over $96 \%$ of the total energy supply. We excluded certain minor categories such as tea, coffee, other sweeteners and spices either because of low energy contribution or lack of information.

In order to check the level of agreement between our calculated values for daily per capita energy, protein and fat supply and the estimates provided on the food balance sheets themselves, we obtained Pearson correlations using Microsoft Office Excel 2003. Statistical significance of correlations was accepted at the 5\% level. All tests were two-sided.

\section{Results}

Fig. 1 shows the relationship between the FAO food balance sheet estimates for (a) energy; (b) protein; and (c) fat supply in the Republic of Ireland and our calculated values using WISP software. Our values for energy supply were,

(a)

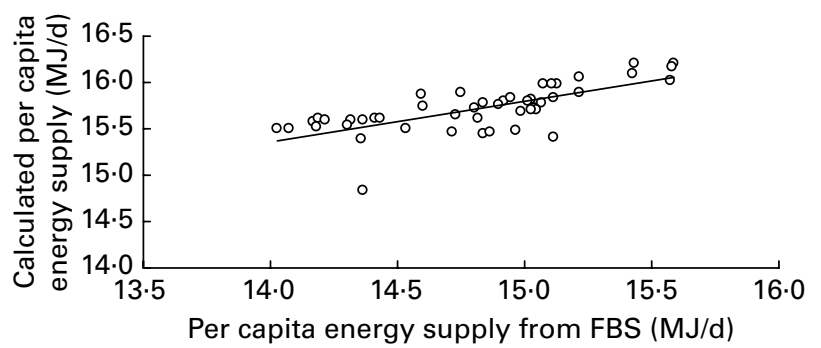

(b)

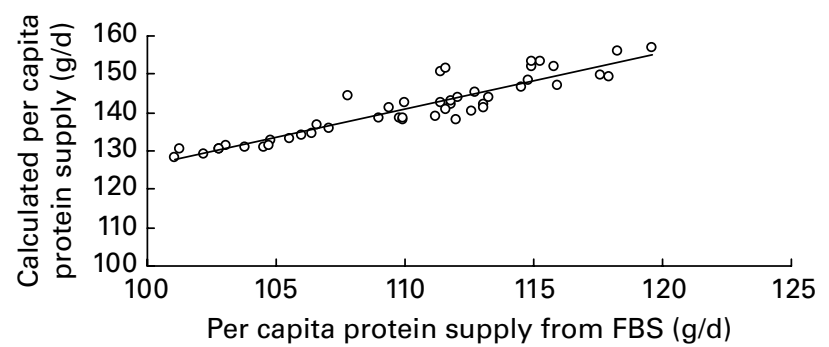

(c)

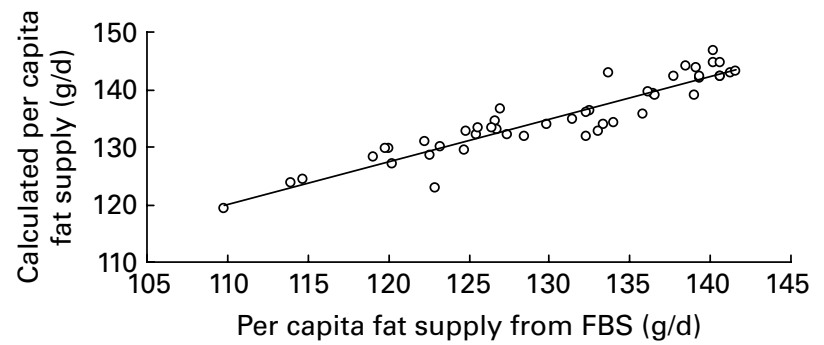

Fig. 1. Relationship between food balance sheet (FBS)-derived and calculated values for (a) energy $(y=0.4316 x+9.3217 ; r 0.7101)$, (b) protein $(y=1.4919 x-23.273 ; r 0.9231)$ and (c) fat $(y=0.7373 x+39.035 ; r 0.9321)$ supply in the Republic of Ireland. (a)

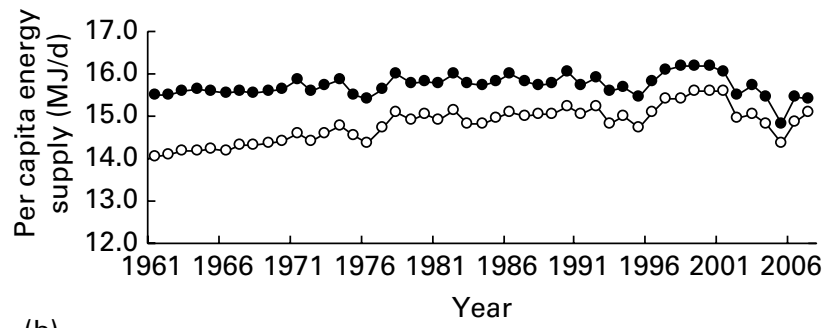

(b)
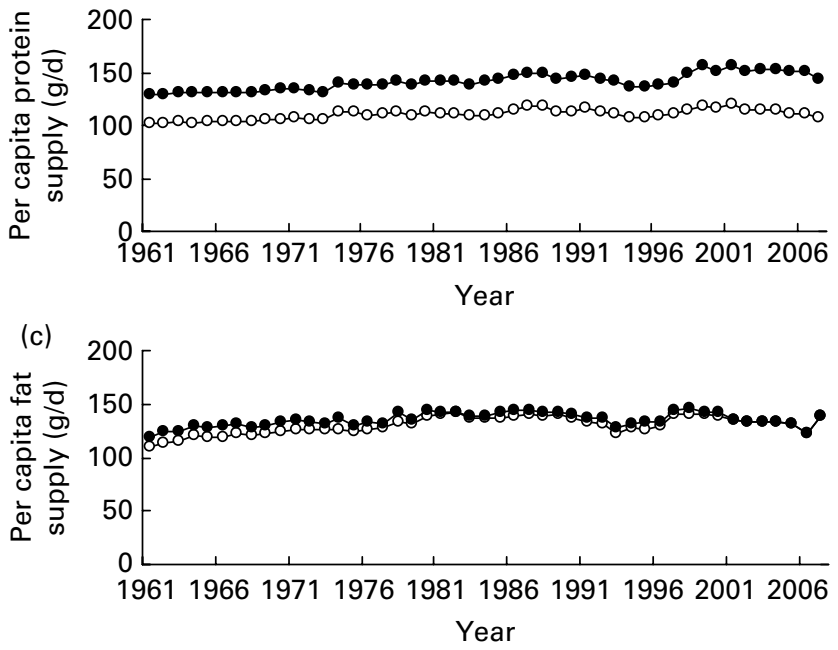

Fig. 2. Trends in food balance sheet-derived (-O-) and calculated (-0-) supply of (a) energy, (b) protein and (c) fat in the Republic of Ireland between 1961 and 2007.

on average, $5.6 \%$ higher than the food balance sheet estimates; however, the relationship between them was statistically significant $(r$ 0.7101; $P<0.0001)$. Our values for protein supply were, on average, $28 \%$ higher than the values shown on the FAO food balance sheets; again, however, the relationship between them was statistically significant ( $r$ 0.9231; $P<0.0001$ ). For fat supply, our calculated values were $3.7 \%$ higher than those shown on the FAO balance sheets; once again, the relationship between them was statistically significant $(r 0.9321 ; P<0.0001)$.

Fig. 2 shows the trends in (a) energy, (b) protein and (c) fat supply between 1961 and 2007 according to the food balance sheets and our calculated values using WISP software. According to the food balance sheets, total per capita energy supply increased by some $1084 \mathrm{~kJ}$ (259 kcal)/d between 1961 and 2007. However, according to our calculations, per capita energy supply in 1961 was actually $67 \mathrm{~kJ}$ (16 kcal) higher than in 2007. This discrepancy between the food balance sheet estimates for energy and our calculated values was evident up to the 1990s; however, the difference between them was minimal after that. Per capita protein supply was about $7 \mathrm{~g} / \mathrm{d}$ higher in 2007 compared with 1961 according to the food balance sheets, and by $16 \mathrm{~g} / \mathrm{d}$ according to our calculations. There was also a gradual increase in per capita fat supply over the same period; fat supply was $29 \mathrm{~g} / \mathrm{d}$ higher in 2007 according to the food balance sheets and approximately $20 \mathrm{~g} / \mathrm{d}$ higher by our calculations. 


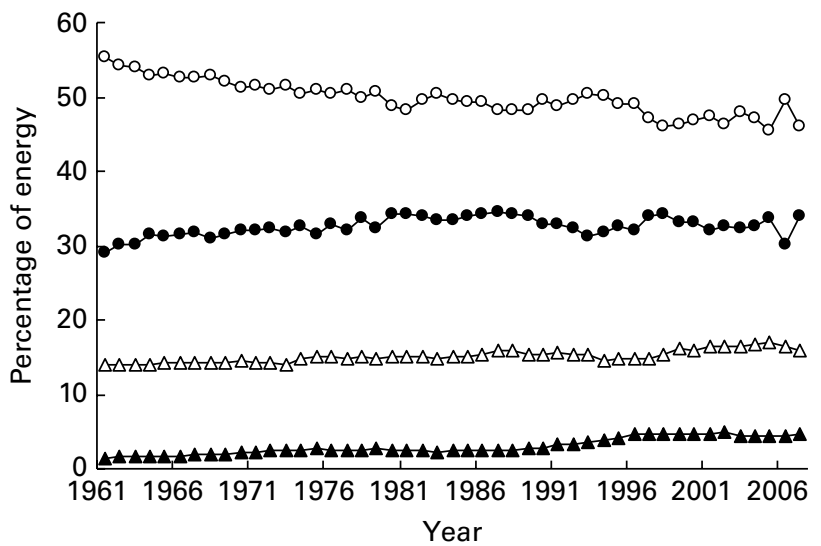

Fig. 3. Calculated percentage contributions to total energy supply of carbohydrate $(-\bigcirc-)$, fat $(-\bullet-)$, protein $(-\triangle-)$ and alcohol $(-\mathbf{\Delta -})$ in the Republic of Ireland from 1961 to 2007.

Fig. 3 shows the calculated percentage contributions of proteins, fats, carbohydrates and alcohol to total energy supply between 1961 and 2007 according to our analysis using WISP software. Energy from carbohydrate fell steadily from $55 \%$ in 1961 to $46 \%$ in 2007 . In contrast, fats provided only about 29\% of energy in 1961 whereas by 2007 this figure had reached $34 \%$. Protein has remained relatively constant at between 14 and $17 \%$ of energy throughout the study period. Alcohol made only a minor contribution of about 1.5$2.5 \%$ of energy up to the mid-1980s but increased steadily since then; in 2007 alcohol contributed $4.6 \%$ of energy.

Fig. 4(a) shows our calculated values for the percentage contribution to energy of SFA, MUFA and PUFA between 1961 and 2007. Between 1961 and the late 1970s the food supply was characterised by a high level of saturated fats ( $>15 \%$ of energy), a moderate level of monounsaturated fats ( $8-10 \%$ of energy) and a low level of polyunsaturated fats $(<3 \%$ of energy). Saturated fats reached a maximum of $16.8 \%$ of energy in 1978 . Between then and the early 1990 s the saturated fat content of the food supply fell to about $12 \%$ of energy while the polyunsaturated fat content rose to $6 \%$ of energy. This resulted in an increase in the polyunsaturated:saturated ratio from 0.16 in 1961 to 0.45 in 1993 . There has been relatively little change in the proportions of saturated, monounsaturated and polyunsaturated fats in the food supply since then. In 2007, saturated fats provided $12.4 \%$ of energy, with monounsaturated and polyunsaturated fats contributing 11.4 and $6 \cdot 8 \%$ of energy, respectively.

Fig. 4(b) shows our calculated values for sugars, starch and fibre supply between 1961 and 2007. Per capita fibre supply fell from $44 \mathrm{~g} / \mathrm{d}$ in 1961 to about $36 \mathrm{~g} / \mathrm{d}$ in 1976 , but has tended to increase since then and in 2007 was $43 \mathrm{~g} / \mathrm{d}$. Energy from sugars fell from 22.3\% of total energy in 1961 to $17.4 \%$ in 2007 . Energy from non-milk extrinsic sugars fell from $16 \%$ of energy in 1961 to $9 \%$ in 2007 . The ratio of sugars: starch has fallen slightly from 0.68 in 1961 to 0.61 in 2007.

Fig. 5(a)-(c) show the trends in fat-soluble vitamin, watersoluble vitamin and mineral supply from 1961 to 2007. Values are expressed on a nutrient-density basis as percentage of the mean WHO/FAO recommendations for male and female adults aged 19-50 years (see Appendix 2) per $10 \mathrm{MJ}$ (2390 kcal) energy. Data for biotin and pantothenic acid are not shown and there was insufficient food composition information to calculate vitamin K supply. Overall, vitamin supply met the recommendations throughout the period apart from vitamin D, folate, vitamin A and vitamin E. Vitamin D supply ranged from 24 to $60 \%$ of the recommendation $(5 \mu \mathrm{g} / \mathrm{d})$ while folate supply varied between 75 and $100 \%$ of the recommendation $(400 \mu \mathrm{g} / \mathrm{d})$. Vitamin $\mathrm{E}$ increased from $78 \%$ of the recommendation $(8.75 \mathrm{mg} / \mathrm{d})$ in 1961 to $153 \%$ in 2007. Vitamin A, on the other hand, fell from $134 \%$ of the recommendation $(550 \mu \mathrm{g} / \mathrm{d})$ in 1981 to $84 \%$ in 2006. All minerals met the recommendations apart from $\mathrm{Ca}$ and $\mathrm{Fe}$. $\mathrm{Ca}$ supply has ranged from 70 to $95 \%$ of the recommendation $(1000 \mathrm{mg} / \mathrm{d})$ while Fe supply has fluctuated between 85 and $105 \%$ of the recommendation $(14.4 \mathrm{mg} / \mathrm{d})$.

Fig. 6 shows the contribution of the major commodities to total energy supply between 1961 and 2007. Wheat contributed $29 \%$ of energy in 1961 but by 1981 its contribution had fallen to $20 \%$, where it has more or less remained ever since. Sugar provided 15\% of energy between 1961 and the early 1970s but since then supply has been in decline; in 2007 sugar provided $7.5 \%$ of energy. Milk provided up to $17 \%$ of energy in the late 1970 s but now provides only about $10 \%$ of energy. Potatoes provided $7 \cdot 6 \%$ of energy in 1961 but by 2007 the value had fallen to $5 \cdot 3 \%$. The overall contribution of meat has increased from 8 to $11 \%$ of energy; within the meat category, mutton's contribution to energy fell from $2 \cdot 0$ to $0.9 \%$, but this was more than offset by the increased popularity of poultry and pig meat (data not shown). The contribution of butter to energy was in gradual decline between 1961 and 1983, falling from 9.5 to $7 \cdot 4 \%$. However, over the next 7 years this value fell sharply to less than $2 \%$ of energy. Butter usage was replaced by rapeseed oil, which rose from $<1 \%$ of energy to approximately $5 \%$ over the same period. Beer contributed $<3 \%$ of energy
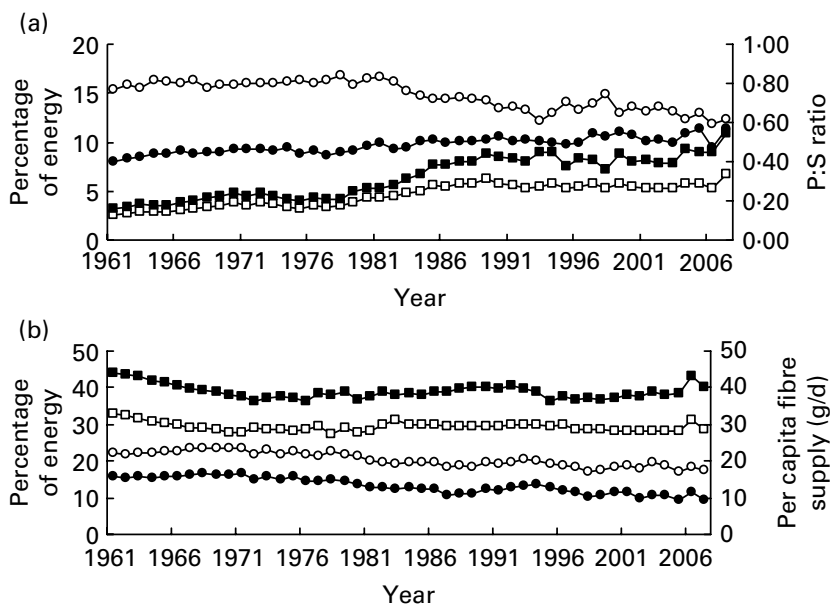

Fig. 4. Calculated trends in (a) per capita supply of SFA (-O-), MUFA (-) ) and PUFA (- $\square-$ ) (all expressed as percentage contribution to energy), and polyunsaturated:saturated (P:S) ratio (-口-), and (b) per capita supply of total sugars $\left(-O_{-}\right)$, non-milk extrinsic sugars $(-\bullet-)$ and starch $(-\square-)$ (all expressed as percentage contribution to energy), and fibre (-ם-; g/d) between 1961 and 2007. 
(a)

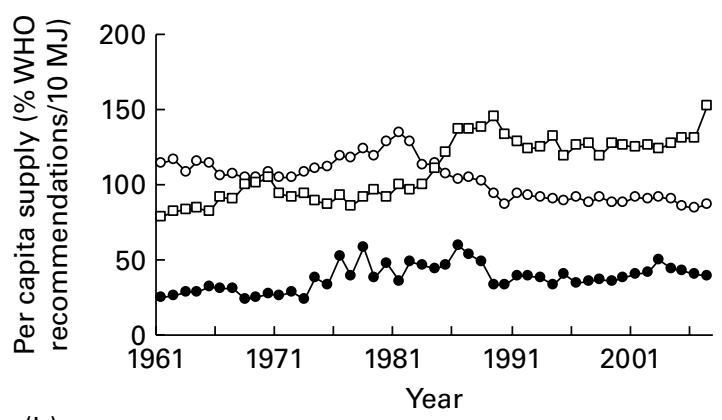

(b)

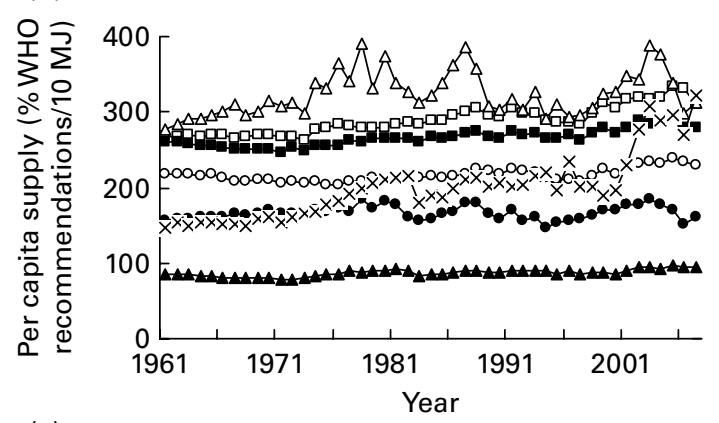

(c)

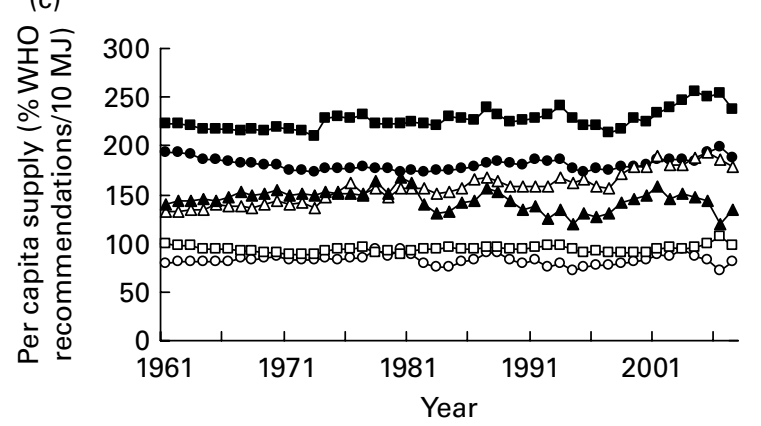

Fig. 5. Per capita supply of (a) fat-soluble vitamins $\left(-\bigcirc_{-}\right.$, vitamin $A ;-\bullet-$, vitamin $\mathrm{D} ;-\square-$, vitamin $\mathrm{E})$, (b) water-soluble vitamins $\left(-\bigcirc-\right.$, vitamin $\mathrm{B}_{1} ;-\bullet_{-}$, vitamin $\mathrm{B}_{2} ;-\square-$, niacin; $-\mathbf{-}-$, vitamin $\mathrm{B}_{6} ;-\Delta-$, vitamin $\mathrm{B}_{12} ;-\mathbf{-}-$, folate; $-\times-$, vitamin $\mathrm{C}$ ) and (c) minerals $(-\mathrm{O}-, \mathrm{Ca}$; $-\bullet-, \mathrm{Mg} ;-\square-$, Fe; - - -, $\mathrm{Zn} ;-\triangle-$, Se; $-\mathbf{\Delta}-$, iodine) in the Irish food supply from 1961 to 2007 . Values are expressed as percentage of WHO recommendations (see Appendix 2) per $10 \mathrm{MJ}$ energy.

between 1961 and the late 1980s but this value more than doubled to $7 \cdot 2 \%$ by 2002 . In 2007 , beer contributed $5.5 \%$ of energy in the Irish food supply.

\section{Discussion}

The objective of the present study was to analyse the commodity data from the FAO food balance sheets for the Republic of Ireland from 1961 to 2007 in order to determine how the country's energy and nutrient supply has changed over recent decades. Overall, there has been a gradual increase in protein and fat supply since the 1960s, consistent with what has happened in most parts of the world ${ }^{(33)}$. For both protein (Fig. 1(b)) and fat (Fig. 1(c)), there were excellent correlations between the values we obtained using WISP dietary analysis software and those provided on the food balance sheets themselves. For energy supply, however
(Fig. 1(a)), the level of agreement was not as good. According to the food balance sheets, per capita energy supply increased by some $1084 \mathrm{~kJ} \quad(259 \mathrm{kcal}) / \mathrm{d}$ between 1961 and 2007 (Fig. 2(a)). Our calculated values, on the other hand, suggest that energy supply hardly changed at all over this time period. On investigating this discrepancy, we discovered that the energy conversion factors used in the Irish food balance sheets for certain important commodities (including wheat, sugar, milk, butter, mutton and potatoes) were at least $10 \%$ lower than those used in WISP software. Also, some were inconsistent. For example, during the 1960s, the average factor for wheat in the food balance sheets was $10 \cdot 88 \mathrm{~kJ} / \mathrm{g}$ $(2.600 \mathrm{kcal} / \mathrm{g})$, whereas during the $1990 \mathrm{~s}$ and $2000 \mathrm{~s}$ it was $\geq 11.30 \mathrm{~kJ} / \mathrm{g}(2.701 \mathrm{kcal} / \mathrm{g})$. The gradual decline in these six commodities as a proportion of the overall food supply (Fig. 6) and the increase in the energy factor for wheat were the main reasons why the curves for energy supply in Fig. 2(a) more or less converged by the end of the 1990s.

In common with most countries, the Republic of Ireland has been experiencing an obesity epidemic in recent decades, the precise cause of which is as yet unknown. Obesity arises as a consequence of how the body regulates energy intake, energy expenditure and energy storage, and increases in obesity rates must reflect a state of positive energy balance ${ }^{(59)}$. The first national nutrition survey in the Republic of Ireland in 1948 reported very high average food energy intakes of approximately $12.97 \mathrm{MJ} / \mathrm{d}(3100 \mathrm{kcal} / \mathrm{d})^{(34)}$, whereas more recently, average daily energy intakes from food were reported to be $9.75 \mathrm{MJ}(2330 \mathrm{kcal})$ in $1990^{(15)}, 9.84 \mathrm{MJ}(2352 \mathrm{kcal})$ in $1998^{(35)}$, $8.79 \mathrm{MJ}(2101 \mathrm{kcal})$ in $1997-99^{(36)}, 9.87 \mathrm{MJ}(2359 \mathrm{kcal})$ in $2002^{(37)}$ and $9.53 \mathrm{MJ}(2278 \mathrm{kcal})$ in $2007^{(16)}$. According to our calculations using WISP software, per capita energy supply in 2007 was $15.40 \mathrm{MJ}(3666 \mathrm{kcal})$, which was lower than energy supply in 1990 (16.05 MJ (3819 kcal)). The corresponding food balance sheet's estimate for energy supply in 2007 was $15 \cdot 11 \mathrm{MJ}(3612 \mathrm{kcal})$, compared with $15 \cdot 21 \mathrm{MJ}(3636 \mathrm{kcal})$ in 1990. These figures suggest that the dramatic increase in obesity rates that occurred over the past two decades did not come about because of an increase in energy intake but

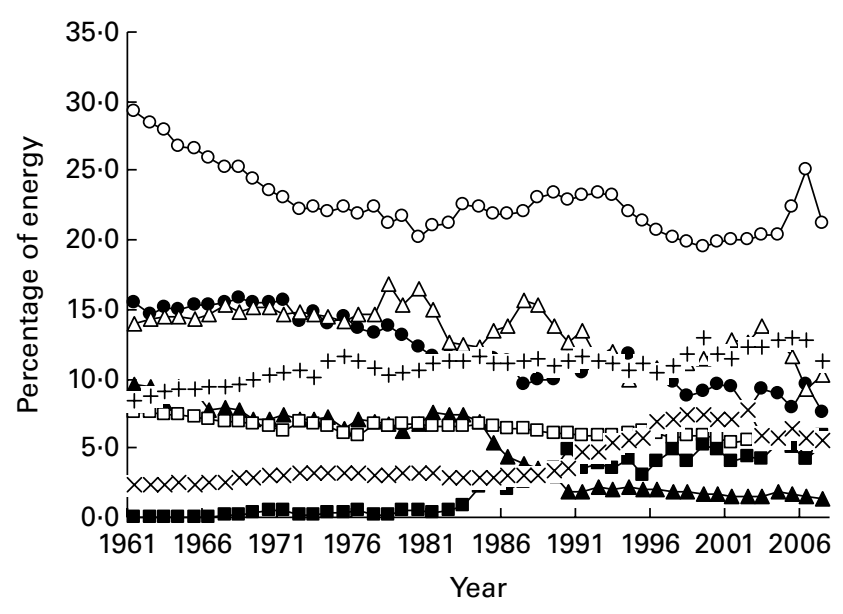

Fig. 6. Percentage contribution of selected commodities (-०-, wheat; - - sugar; $-\triangle-$, milk; $-\mathbf{\Delta}-$, butter; $-\square-$, potatoes; $-\mathbf{-}-$, rapeseed oil; $-\times-$, beer; - + -, meat) to total energy supply in Ireland from 1961 to 2007. 
must be related to reduced physical activity, allied possibly to changes in the macronutrient balance of the food supply. The first comprehensive analysis of habitual physical activity levels (including work, recreational and household activities) in a nationally representative sample of the Irish population was carried out in the late 1990 s and showed that physical activity levels in Irish adults were low, with television viewing occupying most of the leisure time of men and women ${ }^{(60)}$. When physical activity levels in Irish adults were compared across the 1998, 2002 and 2007 SLÁN (Survey of Lifestyle, Attitudes and Nutrition) surveys ${ }^{(16)}$ it was found that the percentage of adults who reported they took no exercise in an average week was 23\% (1998), 28\% (2002) and 19\% (2007), while the percentage reporting moderate and/or strenuous exercise three or more times per week for at least 20 min each time was similar across the three surveys: 38\% (1998), $40 \%$ (2002) and $41 \%$ (2007). Thus it appears that the majority of the Irish population does not partake in sufficient levels of physical activity. It has been hypothesised ${ }^{(59)}$ that biological regulation of energy balance is optimum at a high level of energy flux and there may be a threshold of physical activity below which energy balance regulation is least sensitive. One of the most controversial areas of obesity research is the role of diet composition on body weight. Hill ${ }^{(59)}$ argued that when individuals are in a state of energy balance, a gradual increase in dietary fat could promote weight gain because of the lower thermic effect of fat compared with carbohydrate and the greater voluntary intake associated with high-fat $v$. low-fat diets. Although there has been an increase in the contribution of fat to total energy supply in Ireland since the early 1960 s (Fig. 3), the greater part of this shift occurred before the 1980s, and therefore would appear to have preceded the onset of the obesity epidemic. The increased contribution of alcohol to total energy appears to be more closely related in time to the period when obesity rates began to rise, but whether the relationship was causal or simply a reflection of other societal changes is unclear. The role of alcohol as a risk factor for obesity is controversial ${ }^{(61)}$. In the short term, energy consumed as alcohol is additive to that from other dietary sources, leading to short-term passive overconsumption of energy when alcohol is consumed; indeed, alcohol consumed before or with meals tends to increase food intake. In contrast, epidemiological studies suggest that in the longer term, mild to moderate alcohol intake may be more likely to protect against rather than promote weight gain. Other dietary and environmental factors that may play a role in promoting positive energy balance include high dietary energy density, high-glycaemic diets, sugars from beverages, high-fructose sweeteners, food advertising, and increased food portion sizes, variety, affordability and accessibility ${ }^{(59)}$. Although these factors are clearly relevant with respect to the modern Irish food supply, elucidating their possible contribution to the obesity epidemic requires further study.

Comparing the composition of the Irish food supply with the WHO recommendations, the WHO recommends that $55-70 \%$ of dietary energy should come from carbohydrate and $15-30 \%$ should come from fat ${ }^{(33)}$. The present results (Fig. 3) indicate that only in one particular year (1961) did the Irish food supply meet these recommendations. Since then, energy from carbohydrate has been falling at a rate of about $0.15 \%$ per year, resulting in an overall decrease from $55.4 \%$ of energy in 1961 to $46.1 \%$ in 2007 . On the other hand, energy from fat and protein has been rising at rates of 0.04 and $0.05 \%$ per year, respectively, giving an overall increase from $29 \cdot 2$ to $34.1 \%$ energy from fat and 13.9 to $15.8 \%$ energy from protein over the same time period. These trends have persisted for so long that there appears to be little if any possibility of a significant reversal taking place in the foreseeable future unless major public health nutrition initiatives are put in place to try to redress the balance. Regarding alcohol, the sharp increase in alcohol supply during the 1990s that is evident in Fig. 3 has also been noted by other authors ${ }^{(62)}$. The present results show that these increased levels of alcohol supply were maintained throughout the last decade. This is a very worrying development, as alcohol-related problems cost Irish society in excess of $€ 2.65$ billion in $2003^{(63)}$. The fact that beer contributed more than potatoes to overall energy supply in the Republic of Ireland over the last 10 years (Fig. 6) is truly remarkable.

The WHO recommends that SFA should provide $<10 \%$ of dietary energy and PUFA should provide between 6 and $10 \%$ of energy ${ }^{(33)}$. The present results indicate that quite a dramatic shift in the fatty acid profile of the Irish food supply has occurred over the last 50 years (Fig. 4(a)), bringing it more into line with these recommendations. In 1961, some $15.4 \%$ of energy came from SFA, compared with only 8.0 and $2.5 \%$ from MUFA and PUFA, respectively. However, by 2007 , energy from SFA had fallen to $12 \cdot 4 \%$, while energy from MUFA and PUFA had increased to 11.4 and $6.8 \%$, respectively. The main reason for this shift was the sudden increase in vegetable (in this case, rapeseed) oil supply that occurred during the 1980s (Fig. 6), coupled with the continuous decline in butter usage since the 1960s. Vegetable oil usage increased markedly throughout much of the world during the 1970s and 1980s, fuelled apparently by an aggressive publicity campaign by the vegetable oil industry against saturated fats because of their tendency to raise blood cholesterol, which led to the reformulation of products on a massive scale by food manufacturers ${ }^{(64,65)}$. The changing pattern of fat supply in the Republic of Ireland since the late 1970s has resulted in a doubling of the polyunsaturated: saturated ratio from 0.21 to 0.42 (Fig. 4(a)). Although the polyunsaturated:saturated ratio has been shown to be strongly and inversely related to CHD risk in adults ${ }^{(66)}$, the WHO has not made any recommendations; however, the UK Department of Health recommended that it should be between $0 \cdot 23$ and $0 \cdot 45^{(67)}$.

The sugars content of the Irish diet has been giving cause for concern because of its possible effects on micronutrient dilution and overall diet quality ${ }^{(68)}$. Between 1961 and 2007 the contribution of total sugars to energy in the Irish food supply fell at a rate of about $0.12 \%$ per year from its initial value of $22 \cdot 3 \%$ (Fig. 4(b)). However, sugars still provided $>17 \%$ of energy in 2007 . The WHO recommendation for sugars is that 'free sugars' should provide $<10 \%$ of energy in the diet ${ }^{(33)}$. Free sugars are also referred to as 
non-milk extrinsic sugars, and include all monosaccharides and disaccharides added to foods by the manufacturer, cook or consumer, plus sugars naturally present in honey, syrups and fruit juices. The present results indicate that non-milk extrinsic sugars supply in the Republic of Ireland has been falling, but was still in excess of $10 \%$ of energy every year since 1961 apart from 2002, 2005 and 2007.

The WHO recommendations for fibre are $>25 \mathrm{~g}$ total dietary fibre per $\mathrm{d}$ or $>20 \mathrm{~g}$ NSP per $\mathrm{d}^{(33)}$. The present results show that per capita supply of NSP fell by about $10 \%$ from $44 \cdot 2$ to $40 \cdot 1 \mathrm{~g} / \mathrm{d}$ between 1961 and 2007 (Fig. 4(b)). When expressed on a nutrient-density basis this represents a fall from 28.5 to $26.0 \mathrm{~g}$ per $10 \mathrm{MJ} / \mathrm{d}$. Although these data suggest that fibre supply is adequate, they do not take into account losses that occur after the retail level, such as those due to peeling of fruits and vegetables ${ }^{(49)}$.

Recent studies ${ }^{(16,69-79)}$ have drawn attention to the fact that certain sections of the Irish population have inadequate intakes of micronutrients, the most important being vitamin $\mathrm{D}$, folate, $\mathrm{Ca}$ and $\mathrm{Fe}^{(16)}$. The present results (Fig. 5(a)-(c)) show that for the majority of micronutrients, per capita supply (expressed per 10 MJ energy) exceeded WHO recommendations $^{(80)}$ throughout the period between 1961 and 2007. However, supplies of Ca, vitamin D and folate were below the WHO recommendations - substantially so in the case of vitamin D - and Fe has been borderline. Ca is required for normal growth and development as well as maintenance of the skeleton, and evidence indicates that dietary $\mathrm{Ca}$ intake is inadequate for maintenance of bone health in a substantial proportion of some population groups in Ireland, particularly adolescent girls and older women ${ }^{(81)}$. Vitamin D is essential for intestinal $\mathrm{Ca}$ absorption and the maintenance of Ca homeostasis and skeletal integrity ${ }^{(82)}$. Cutaneous synthesis of vitamin D from sunlight exposure in the Republic of Ireland is limited because of the country's geographic location (approximately $51-55^{\circ} \mathrm{N}$ ) and cloudy climate, and there is a reliance on dietary sources during the winter months to help maintain adequate vitamin D status. Poor vitamin D status has been reported in a number of subgroups in the Irish population, including pregnant women ${ }^{(79)}$, children and adolescents ${ }^{(83)}$ and older individuals ${ }^{(83-86)}$, and vitamin $\mathrm{D}$ insufficiency is also widespread in the general adult population, especially during wintertime ${ }^{(87)}$. Recent studies have shown that dietary vitamin D intakes of at least $7 \cdot 2 \mu \mathrm{g} / \mathrm{d}$ are required to maintain serum 25-hydroxyvitamin D concentrations above even the lowest $(25 \mathrm{nmol} / \mathrm{l})$ cut-off point for adequacy during wintertime in the vast majority $(>97.5 \%)$ of Irish adults ${ }^{(88)}$. The present results indicate that the level of vitamin $\mathrm{D}$ in the food supply over the last four decades has been consistently lower than this $(<3 \mu \mathrm{g} / 10 \mathrm{MJ}$ energy). With increasing attention being focused on diseases associated with ageing, and the baseline cost of falls and fractures in older individuals being estimated at over $€ 400$ million per annum ${ }^{(89)}$, there is clearly a need for strategies to increase the vitamin D and Ca status of the Irish population. The critical role of folate in preventing neural tube defects (NTD) is well established ${ }^{(90-94)}$. For almost two decades health authorities have been recommending that women who could become pregnant should increase their dietary folate intake and take a daily supplement of $400 \mu \mathrm{g}$ folic acid ${ }^{(95-97)}$. The Republic of Ireland has higher rates of NTD-affected pregnancies than many other European countries, and because the option of termination is illegal this makes primary prevention an important issue ${ }^{(98)}$. Recognition that typical folate intakes in the Republic of Ireland are suboptimal for NTD prevention and that health promotion campaigns aimed at increasing folic acid supplement intake have been ineffective led to a recommendation - accepted by Government - to initiate mandatory folic acid fortification of bread ${ }^{(99)}$. However, this decision was later put on hold because of emerging concerns about the safety of high folic acid intake ${ }^{(100)}$. According to our calculations, the folate content of the Irish food supply has increased from about 320 to $380 \mu \mathrm{g} / 10 \mathrm{MJ}$ energy since the early 1970s, a period during which NTD prevalence has declined significantly ${ }^{(101)}$; however, it remains well below the levels deemed optimal for NTD prevention. Unless the decision to suspend the roll-out of mandatory fortification is reversed, or voluntary folic acid fortification by food companies is increased considerably (both of which appear unlikely), or unless other effective ways of increasing the folate status of women of child-bearing age are identified, Irish women will continue to be inadequately protected against the risk of having avoidable NTD-affected pregnancies.

Overall, it is evident from the present study that there are long-standing imbalances in the Irish food supply in comparison with WHO recommendations ${ }^{(33)}$ and that public health action will be needed to prevent the adverse consequences of these inappropriate dietary patterns and physical inactivity. The WHO recommends a number of policy principles that should be considered when developing national strategies to reduce the burden of diet- and physical inactivity-related chronic diseases ${ }^{(33)}$. These principles include the need for governments to work together with the private sector, health professional bodies, consumer groups, academics, the research community and other non-governmental bodies in addressing risk factors, the need to adopt a life-course perspective on chronic disease prevention, and the need to diminish inequalities in society by focusing on the poorest communities and population groups. Strategic actions recommended by the WHO for promoting healthy diets and physical activity include carrying out ongoing nutrition surveillance, providing effective communication of information about food composition and quality, applying strict codes of practice in food labelling and advertising, encouraging intersectoral alliances to ensure that healthy diet components are available and affordable to all, and providing adequate training about diet, nutrition and physical activity to all health professionals. Approaches to promoting healthier diets and lifestyles in the Republic of Ireland should follow these principles.

There are a number of limitations to the present study. As mentioned earlier, food balance sheets overestimate food consumption and nutrient intakes because they fail to take into account food waste or spoilage or other losses that occur after the retail level ${ }^{(49)}$. Also, they only allow for per capita estimates and lack the information necessary to analyse the population by sex, age and socio-economic status. In addition, 
the present results for micronutrients are limited by the fact that food balance sheets provide no information on either bioavailability or fortification. For these reasons, it is not possible to make direct comparisons between data derived from food balance sheets and those from food consumption surveys because each approach measures different levels of dietary information. To try to overcome this limitation and facilitate at least some sort of comparison, we presented our data in relative terms (for example, as percentage of total energy, as ratios, or per $10 \mathrm{MJ}$ energy, as appropriate). Another limitation of food balance sheets is that foods are listed as basic commodities rather than the specific products that individuals eat. This presents a challenge as regards how to code the data properly for nutritional analysis. For consistency, we coded at the level of the raw unprocessed commodity wherever possible; however, we acknowledge that this could lead to an overestimation of some components, for example, fibre. Another important limitation is the lack of detail regarding certain commodities, such as types of fish, fruits and vegetables. To try to overcome this issue we populated these categories using information about commonly consumed foods from a QFFQ developed specifically for an Irish population. Although this could only give an approximation of true supply for these categories it ensured that foods typically consumed in the Republic of Ireland but which were not already specifically accounted for in the food balance sheets would be represented. Table 1 compares the results for macronutrients and selected micronutrients from the five most recent national nutrition surveys in Ireland with our corresponding results for those same dates. Bearing in mind the above limitations and the different methodologies involved, there was very good agreement on the whole between these two sets of figures, which suggests that the trends in nutrient supply that we have presented here are likely to be a reasonable reflection of what has actually occurred over the past 50 years.

In conclusion, the present study sheds new light on the changes in energy and nutrient supply that have taken place in the Republic of Ireland since the early 1960s. There has been a substantial decrease in the proportion of energy derived from carbohydrates; a corresponding increase in energy from fat and (more recently) alcohol; a reduction in SFA with an overall improvement in the fatty acid profile; and slight reductions in both sugars and fibre. On a nutrient-density basis, vitamins and minerals met or exceeded WHO recommendations, apart from vitamin D, folate, Ca and Fe. Surprisingly, considering the dramatic increase in obesity rates that has occurred within the last 20 years, there was little evidence of any increase in per capita energy supply over the same period. The imbalances that currently exist in the Irish food supply, especially in relation to fat and carbohydrates but also with regard to certain micronutrients, became established or were already evident several decades ago; for this reason they will not be resolved easily or quickly. It would appear that major public health nutrition initiatives will be needed to bring the Irish diet into line with WHO recommendations for the prevention of chronic disease. 


\section{Acknowledgements}

This research received no specific grant from any funding agency in the public, commercial or not-for-profit sectors.

The authors express their sincere gratitude to FAOSTAT, Statistics Division of the FAO, for allowing them to use their data, and to the anonymous referees who reviewed the manuscript for their helpful comments.

T. S. and S. S. conceived and designed the study. T. S. collated and analysed the data and drafted the manuscript. S. S. critically reviewed the manuscript and contributed to its revision.

The authors declare that they have no conflicts of interest.

\section{References}

1. World Bank (2010) GDP per capita (current US\$). http:// data.worldbank.org/indicator/NY.GDP.PCAP.CD (accessed August 2010).

2. Murphy AE (2000) The 'Celtic Tiger' - an analysis of Ireland's economic growth performance. RSC no. 2000/16. Robert Schuman Centre of Advanced Studies. http://www. eui.eu/RSCAS/WP-Texts/00_16.pdf (accessed September 2010).

3. Central Statistics Office (2010) Gross domestic product and gross national product at 2008 prices by quarter and statistic. http://www.cso.ie/releasespublications/documents/ economy/current/qna.pdf (accessed September 2010).

4. World Bank (2010) Life expectancy at birth, total (years). http://data.worldbank.org/sites/default/files/indicators/en/ life-expectancy-at-birth-total-years_en.xls (accessed August 2010).

5. Creagh D, Neilson S, Collins A, et al. (2002) Established cardiovascular disease and CVD risk factors in a primary care population of middle-aged Irish men and women. Ir Med J 95, 298-301.

6. Hall M, McGettigan M, O'Callaghan P, et al. (2002) Comparison of secondary prevention of heart disease in Europe: lifestyle getting worse, therapy getting better in Ireland. Ir Med J 95, 272-274.

7. McCarthy SN, Gibney MJ, Flynn A, et al. (2002) Overweight, obesity and physical activity levels in Irish adults: evidence from the North/South Ireland food consumption survey. Proc Nutr Soc 61, 3-7.

8. Department of Health and Children (2005) Report of the National Taskforce on Obesity: Obesity - the policy challenges. http://www.dohc.ie/publications/report_ taskforce_on_obesity_es.html (Accessed August 2010).

9. Nolan JJ, O'Halloran D, McKenna TJ, et al. (2006) The cost of treating type 2 diabetes (CODEIRE). Ir Med $J$ 99, 307-310.

10. Perry IJ, Whelton H, Harrington J, et al. (2009) The heights and weights of Irish children from the post-war era to the Celtic tiger. J Epidemiol Community Health 63, 262-264.

11. Office of the Houses of the Oireachtas (2010) Dáil Eireann Debate Vol. 706 No. 2. Thursday, 1 April 2010. Obesity Levels: Statements. http://debates.oireachtas.ie/dail/2010/04/ 01/00008.asp (accessed March 2011).

12. Bennett K, Kabir Z, Unal B, et al. (2006) Explaining the recent decrease in coronary heart disease mortality rates in Ireland, 1985-2000. J Epidemiol Community Health 60, 322-327.

13. Kabir Z, Bennett K, Shelley E, et al. (2007) Life-years-gained from population risk factor changes and modern cardiology treatments in Ireland. Eur J Public Health 17, 193-198.
14. Kabir Z, Bennett K, Shelley E, et al. (2007) Comparing primary prevention with secondary prevention to explain decreasing coronary heart disease death rates in Ireland, 1985-2000. BMC Public Health 7, 117.

15. Lee P \& Cunningham K (1990) Irish National Nutrition Survey. Dublin: Irish Nutrition and Dietetic Institute.

16. Morgan K, McGee H, Watson D, et al. (2008) SLÁN 2007, Survey of Lifestyle, Attitudes and Nutrition in Ireland. Main Report, Department of Health and Children. Dublin: The Stationery Office.

17. Whelton H, Harrington J, Crowley E, et al. (2007) Prevalence of overweight and obesity on the island of Ireland: results from the North South Survey of Children's Height, Weight and Body Mass Index, 2002. BMC Public Health 7, 187.

18. O'Neill JL, McCarthy SN, Burke SJ, et al. (2007) Prevalence of overweight and obesity in Irish school children, using four different definitions. Eur J Clin Nutr 61, 743-751.

19. World Health Organization (2006) What are the health consequences of being overweight? http://www.who.int/ features/qa/49/en/index.html (accessed January 2011).

20. Ireland-Northern Ireland-National Cancer Institute Cancer Consortium (2010) About the Consortium. http://www. allirelandnci.com/about_consortium/index.asp (accessed January 2011).

21. Donnelly DW, Gavin AT \& Comber H (2009) Cancer in Ireland 1994-2004, a Comprehensive Report. Cork, Republic of Ireland: National Cancer Registry, Ireland.

22. Irish Heart Foundation (2007) Mortality from cardiovascular disease (CVD) i.e. from coronary heart disease, stroke and other diseases of the circulation in 2006. http://www. irishheart.ie/iopen24/pub/factsheets/cvd_mortality_rates_ 2007.pdf (accessed January 2011).

23. Health Service Executive (2011) Ireland Take Heart, an audit of the implementation of Building Healthier Hearts: percentage decline in CHD mortality in Ireland between the time periods 1994-1998 and 1999-2003. http://www. hse.ie/eng/staff/FactFile/Health_Status_Reports/Population_ Health/Cardiovascular_Care_/Ireland_Take_Heart/\#percentagedecline (accessed January 2011).

24. Bennett K, Johnson H, Dack P, et al. (2005) Changes in prevalence of and prescribing for ischaemic heart disease in Ireland 1990-2002. Ir J Med Sci 174, 4-8.

25. Balanda KP, Barron S, Fahy L, et al. (2010) Making Chronic Conditions Count: Hypertension, Stroke, Coronary Heart Disease, Diabetes. A Systematic Approach to Estimating and Forecasting Population Prevalence on the Island of Ireland. Dublin: Institute of Public Health in Ireland.

26. Zaharan NL, Mahmud A, Bennett K, et al. (2009) Hypertension in Ireland: public awareness and doctors' choice of therapy. Ir J Med Sci 178, 413-417.

27. International Diabetes Federation (2000) Maps: Diabetes Atlas 1st edition. http://www.diabetesatlas.org/sites/default/ files/IDF\%20Diabetes\%20Atlas-2000\%20(1st\%20edition).pdf (accessed February 2011).

28. International Diabetes Federation (2010) Maps: Diabetes Atlas 4th edition. http://www.diabetesatlas.org/map (accessed February 2011).

29. Balanda KP, Fahy L \& Jordan A, et al. (2006) Making Diabetes Count: a systematic approach to estimating and forecasting population prevalence on the island of Ireland in 2005. Dublin: Institute of Public Health in Ireland. http://www.inispho.org/node/410 (accessed January 2011).

30. Genuis SJ (2005) Nutritional transition: a determinant of global health. J Epidemiol Community Health 59, 615-617. 
31. Office of the Surgeon General (1988) The Surgeon General's Report on Nutrition and Health. Public Health and Disease Prevention. Publication no. 88-50210:1-750 Washington, DC: Department of Health and Human Services (PHS).

32. Centers for Disease Control and National Center for Chronic Disease Prevention and Health Promotion (2003) Physical activity and good nutrition: essential elements to prevent chronic diseases and obesity 2003. Nutr Clin Care 6, $135-138$.

33. World Health Organization (2003) Diet, Nutrition and the Prevention of Chronic Diseases. Joint WHO/FAO Expert Consultation. WHO Technical Report Series no. 916. Geneva: WHO.

34. Department of Health (1948) National Nutrition Survey. Dublin: Stationery Office.

35. Friel S, Nic Gabhainn S \& Kelleher C (1999) The National Health and Lifestyles Surveys. Survey of Lifestyle, Attitudes and Nutrition (SLÁN) and the Irish Health Behaviour in School-aged Children (HBSC) Survey 1998, Department of Health and Children. Dublin: The Stationery Office.

36. Harrington KE, Robson PJ, Kiely M, et al. (2001) The North/ South Ireland Food Consumption Survey: survey design and methodology. Public Health Nutr 4, 1037-1042.

37. Kelleher C, Nic Gabhainn S, Friel S, et al. (2003) The National Health and Lifestyles Surveys. Survey of Lifestyle, Attitudes and Nutrition (SLÁN) and the Irish Health Behaviour in School-aged Children (HBSC) Survey 2002, Department of Health and Children. Dublin: The Stationery Office.

38. Hiller JE \& McMichael AJ (1997) Ecological studies. In Design Concepts in Nutritional Epidemiology, 2nd ed., pp. 323-353 [B Margetts and M Nelson, editors]. Oxford: Oxford University Press.

39. Food and Agriculture Organization (2001) Food balance sheets: a handbook. Rome: FAO. http://www.fao.org/ docrep/003/x9892e/x9892e00.htm (accessed August 2010).

40. Jacobs K \& Sumner DA (2002) The food balance sheets of the Food and Agriculture Organization: a review of potential ways to broaden the appropriate uses of the data. http://faostat.fao.org/abcdq/docs/FBS_Review.pdf (accessed August 2010).

41. Zizza C (1997) The nutrient content of the Italian food supply 1961-1992. Eur J Clin Nutr 51, 259-265.

42. Al-Hooti SN (2002) Food consumption pattern for the population of the State of Kuwait based on food balance sheets. Ecol Food Nutr 41, 501-514.

43. Rodler I \& Zajkás G (2002) Hungarian cancer mortality and food availability data in the last four decades of the 20th century. Ann Nutr Metab 46, 49-56.

44. Männistö S, Laatikainen T, Helakorpi S, et al. (2010) Monitoring diet and diet-related chronic disease risk factors in Finland. Public Health Nutr 13, 907-914.

45. Sheehy T \& Sharma S (2010) The nutrition transition in Barbados: trends in macronutrient supply from 1961 to 2003. Br J Nutr 104, 1222-1229.

46. Popkin BM (1998) The nutrition transition and its health implications in lower-income countries. Public Health Nutr 1, 5-21.

47. Kennedy G (2002) Global trends in dietary energy supply from 1961 to 1999. Food Nutr Agric (FAO) 30, 53-64.

48. Garcia-Closas R, Berenguer A \& González CA (2006) Changes in food supply in Mediterranean countries from 1961 to 2001. Public Health Nutr 9, 53-60.

49. Schmidhuber J \& Traill WB (2006) The changing structure of diets in the European Union in relation to healthy eating guidelines. Public Health Nutr 9, 584-595.
50. Balanza R, García-Lorda P, Pérez-Rodrigo C, et al. (2007) Trends in food availability determined by the Food and Agriculture Organization's food balance sheets in Mediterranean Europe in comparison with other European areas. Public Health Nutr 10, 168-176.

51. Chen Q \& Marques-Vidal P (2007) Trends in food availability in Portugal in 1966-2003: comparison with other Mediterranean countries. Eur J Nutr 46, 418-427.

52. Mazzocchi M, Brasili C \& Sandri E (2008) Trends in dietary patterns and compliance with World Health Organization recommendations: a cross-country analysis. Public Health Nutr 11, 535-540.

53. Ulijaszek SJ \& Koziel S (2007) Nutrition transition and dietary energy availability in Eastern Europe after the collapse of communism. Econ Hum Biol 5, 359-369.

54. Asfaw A (2008) Fruits and vegetables availability for human consumption in Latin American and Caribbean countries: patterns and determinants. Food Policy 33, 444-454.

55. Naska A, Berg MA, Cuadrado C, et al. (2009) Food balance sheet and household budget survey dietary data and mortality patterns in Europe. Br J Nutr 102, 166-171.

56. da Silva R, Bach-Faig A, Raidó Quintana B, et al. (2009) Worldwide variation of adherence to the Mediterranean diet, in 1961-1965 and 2000-2003. Public Health Nutr 12, 1676-1684.

57. FAOSTAT (2010) Food balance sheets. http://faostat.fao. org/site/368/default.aspx (accessed August 2010).

58. Food Standards Agency (2002) McCance and Widdowson's Composition of Foods, 6th ed. Cambridge: Royal Society of Chemistry.

59. Hill JO (2006) Understanding and addressing the epidemic of obesity: an energy balance perspective. Endocr Rev 27, $750-761$.

60. Livingstone MB, Robson PJ, McCarthy S, et al. (2001) Physical activity patterns in a nationally representative sample of adults in Ireland. Public Health Nutr 5A, 1107-1116.

61. Yeomans MR (2010) Alcohol, appetite and energy balance: is alcohol intake a risk factor for obesity? Physiol Behav 100, 82-89.

62. Harrington KE, McGowan MJ, Kiely M, et al. (2001) Macronutrient intakes and food sources in Irish adults: findings of the North/South Ireland Food Consumption Survey. Public Health Nutr 4, 1051-1060.

63. Department of Health and Children (2004) Strategic Task Force on Alcohol. Second Report. Dublin: The Stationery Office.

64. Fife B (2004) The truth about coconut oil. In The Coconut Oil Miracle, pp. 5-16 [B Fife, editor]. New York: Avery Publishing Company.

65. Fife BF (2006) Coconut oil and health. Proceedings of the International Coconut Forum. 22-24 November 2005, Cairns, Australia. ACIAR Proc 125, 49-56.

66. Hu FB, Stampfer MJ, Manson JE, et al. (1999) Dietary saturated fats and their food sources in relation to the risk of coronary heart disease in women. Am J Clin Nutr 70, 1001-1008.

67. Department of Health (1984) Diet and Cardiovascular Disease. Committee on Medical Aspects of Food Policy Report on Health and Social Subjects no. 28. London: H.M. Stationery Office.

68. Joyce T \& Gibney MJ (2008) The impact of added sugar consumption on overall dietary quality in Irish children and teenagers. J Hum Nutr Diet 21, 438-450.

69. Hurson M, Corish C \& Sugrue S (1997) Dietary intakes in Ireland of a healthy elderly population. Ir J Med Sci $\mathbf{1 6 6}$ 220-224. 
70. Hannon EM, Kiely M, Harrington KE, et al. (2001) The North/ South Ireland Food Consumption Survey: mineral intakes in 18-64-year-old adults. Public Health Nutr 4, 1081-1088.

71. Kiely M, Flynn A, Harrington KE, et al. (2001) The efficacy and safety of nutritional supplement use in a representative sample of adults in the North/South Ireland Food Consumption Survey. Public Health Nutr 4, 1089-1097.

72. O'Brien MM, Kiely M, Harrington KE, et al. (2001) The North/ South Ireland Food Consumption Survey: vitamin intakes in 18-64-year-old adults. Public Health Nutr 4, 1069-1079.

73. Murphy J, Hannon EM, Kiely M, et al. (2002) Selenium intakes in 18-64-y-old Irish adults. Eur J Clin Nutr 56, 402-408.

74. Duggan P, Cashman KD, Flynn A, et al. (2004) Phylloquinone (vitamin $\mathrm{K}_{1}$ ) intakes and food sources in 18-64year-old Irish adults. Br J Nutr 92, 151-158.

75. Hill TR, O'Brien MM, Cashman KD, et al. (2004) Vitamin D intakes in 18-64-y-old Irish adults. Eur J Clin Nutr 58, $1509-1517$

76. Hill T, Collins A, O'Brien M, et al. (2005) Vitamin D intake and status in Irish postmenopausal women. Eur J Clin Nutr 59, 404-410.

77. McCarthy D, Collins A, O'Brien M, et al. (2006) Vitamin D intake and status in Irish elderly women and adolescent girls. Ir J Med Sci 175, 14-20.

78. McNulty H \& Scott JM (2008) Intake and status of folate and related B-vitamins: considerations and challenges in achieving optimal status. Br J Nutr 99, Suppl. 3, S48-S54.

79. O'Riordan MN, Kiely M, Higgins JR, et al. (2008) Prevalence of suboptimal vitamin D status during pregnancy. Ir Med J 240, 242-243.

80. World Health Organization and Food and Agriculture Organization (2004) Vitamin and mineral requirements in human nutrition: report of a joint FAO/WHO expert consultation, Bangkok, Thailand, 21-30 September 1998. http://whqlibdoc.who.int/publications/2004/9241546123_ annexes.pdf (accessed August 2010).

81. Flynn A (2003) The role of dietary calcium in bone health. Proc Nutr Soc 62, 851-858.

82. Cashman KD (2007) Calcium and vitamin D. Novartis Found Symp 282, 123-138.

83. Andersen R, Mølgaard C, Skovgaard LT, et al. (2005) Teenage girls and elderly women living in northern Europe have low winter vitamin D status. Eur J Clin Nutr 59, 533-541.

84. Romero-Ortuno R, Cogan L, Browne J, et al. (2011) Seasonal variation of serum vitamin $D$ and the effect of vitamin D supplementation in Irish community-dwelling older people. Age Ageing 40, 168-174.

85. Lardner E, Fitzgibbon M, Wilson S, et al. (2011) Hypovitaminosis $\mathrm{D}$ in a healthy female population, aged from 40 to 85 years, in the west of Ireland. Ir J Med Sci 180, 115-119.

86. O'Malley G \& Mulkerrin E (2011) Vitamin D insufficiency: a common and treatable problem in the Irish population. Ir J Med Sci 180, 7-13.
87. O'Sullivan M, Nic Suibhne T, Cox G, et al. (2008) High prevalence of vitamin $\mathrm{D}$ insufficiency in healthy Irish adults. Ir J Med Sci 177, 131-134.

88. Cashman KD, Hill TR, Lucey AJ, et al. (2008) Estimation of the dietary requirement for vitamin $\mathrm{D}$ in healthy adults. Am J Clin Nutr 88, 1535-1542.

89. Gannon B, O'Shea E \& Hudson E (2008) Economic consequences of falls and fractures among older people. Ir Med J 101, 170-173.

90. Anonymous (1991) Prevention of neural tube defects: results of the Medical Research Council Vitamin Study. MRC Vitamin Study Research Group. Lancet 338, 131-137.

91. Czeizel AE \& Dudás I (1992) Prevention of the first occurrence of neural-tube defects by periconceptional vitamin supplementation. $N$ Engl J Med 327, 1832-1835.

92. Werler MM, Shapiro S \& Mitchell AA (1993) Periconceptional folic acid exposure and risk of occurrent neural tube defects. JAMA 269, 1257-1261.

93. Berry RJ, Li Z, Erickson JD, et al. (1999) Prevention of neural-tube defects with folic acid in China. China-U.S. Collaborative Project for Neural Tube Defect Prevention. $N$ Engl J Med 341, 1485-1490.

94. Oakley GP Jr (2009) The scientific basis for eliminating folic acid-preventable spina bifida: a modern miracle from epidemiology. Ann Epidemiol 19, 226-230.

95. Department of Health Expert Advisory Group (1992) Folic Acid and the Prevention of Neural Tube Defects. London: Department of Health.

96. Centers for Disease Control (1992) Recommendations for the use of folic acid to reduce the number of cases of spina bifida and other neural tube defects. MMWR 41, RR-14.

97. National Health and Medical Research Council (1993) Revised Statement on the Relationship Between Dietary Folic Acid and Neural Tube Defects Such as Spina Bifida. 115th session. Canberra: National Health and Medical Research Council.

98. Flynn MA, Anderson WA, Burke SJ, et al. (2008) Session 1: Public health nutrition. Folic acid food fortification: the Irish experience. Proc Nutr Soc 67, 381-389.

99. Food Safety Authority of Ireland (2006) Report of the National Committee on Folic Acid Food Fortification. Dublin: Food Safety Authority of Ireland. http://www.fsai. ie/uploadedfiles/folic_acid.pdf (accessed January 2011).

100. Food Safety Authority of Ireland (2008) Report of the Implementation Group on Folic Acid Food Fortification to the Department of Health and Children. Dublin: Food Safety Authority of Ireland. http://staging.fsai.ie/WorkArea/ linkit.aspx?LinkIdentifier $=\mathrm{id} \& I t e m I D=7602$ (accessed January 2011).

101. Cotter AM \& Daly SF (2005) Neural tube defects: is a decreasing prevalence associated with a decrease in severity? Eur J Obstet Gynecol Reprod Biol 119, 161-163. 


\section{Appendix 1. Commodities listed in FAO food balance sheets}

Cereals - excluding beer: wheat; rice (milled equivalent); barley; maize; rye; oats; millet; sorghum; cereals (other)

Starchy roots: cassava; potatoes; sweet potatoes; yams; roots (other)

Sugar crops: sugar cane; sugar (raw equivalent); sweeteners (other); honey

Pulses: beans; peas; pulses (other); treenuts

Oilcrops: soyabeans; groundnuts (shelled equivalent); sunflower seed; rape and mustard seed; coconuts - including copra; sesame seed; olives; oilcrops (other)

Vegetable oils: soyabean oil; groundnut oil; sunflower seed oil; rape and mustard oil; cottonseed oil; palm oil; coconut oil; sesame seed oil; olive oil; maize germ oil; oilcrops oil (other)

Vegetables: tomatoes; onions; vegetables (other)

Fruits - excluding wine: oranges; lemons; grapefruit; citrus (other); bananas; plantains; apples; pineapples; dates; grapes; fruits (other)

Stimulants: coffee; cocoa beans; tea

Spices: pepper; pimento; cloves; spices (other)

Alcoholic beverages: wine; beer; beverages (fermented); beverages (alcoholic)

Meat: bovine meat; mutton and goat meat; pig meat; poultry meat; meat (other); offals (edible)

Animal fats: butter, ghee; cream; animal fats (raw); fish body oil; fish liver oil

Milk - excluding butter

Eggs

Fish, seafood: freshwater fish: demersal fish; pelagic fish; marine fish; other

Crustaceans: cephalopods; molluscs, other

Miscellaneous

Appendix 2. Recommended nutrient intakes ${ }^{(80)}$

\begin{tabular}{|c|c|c|c|}
\hline Nutrient & Female (age $19-50$ years) & Male (age $19-50$ years) & Mean \\
\hline $\mathrm{Ca}(\mathrm{mg})$ & 1000 & 1000 & 1000 \\
\hline $\mathrm{Mg}(\mathrm{mg})$ & 220 & 260 & 240 \\
\hline $\mathrm{Fe}(\mathrm{mg})-$ assuming $15 \%$ bioavailability & $19 \cdot 6$ & $9 \cdot 1$ & 14.4 \\
\hline $\mathrm{Zn}(\mathrm{mg})$ - assuming moderate bioavailability & 4.9 & 7 & 6 \\
\hline Se $(\mu \mathrm{g})$ & 26 & 34 & 30 \\
\hline lodine $(\mu \mathrm{g})$ & 150 & 150 & 150 \\
\hline Vitamin A ( $\mu$ g retinol equivalents) & 500 & 600 & 550 \\
\hline Vitamin D $(\mu \mathrm{g})$ & 5 & 5 & 5 \\
\hline Vitamin E (mg $\alpha$-tocopherol equivalents) & 7.5 & 10 & 8.75 \\
\hline Thiamin (mg) & $1 \cdot 1$ & $1 \cdot 2$ & $1 \cdot 15$ \\
\hline Riboflavin (mg) & $1 \cdot 1$ & 1.3 & $1 \cdot 2$ \\
\hline Niacin (mg niacin equivalents) & 14 & 16 & 15 \\
\hline Vitamin $B_{6}(m g)$ & 1.3 & 1.3 & 1.3 \\
\hline Vitamin $B_{12}(\mu \mathrm{g})$ & 2.4 & $2 \cdot 4$ & 2.4 \\
\hline Folate ( $\mu \mathrm{g}$ dietary folate equivalents) & 400 & 400 & 400 \\
\hline Vitamin C (mg) & 45 & 45 & 45 \\
\hline
\end{tabular}

